\title{
PROSPECTIVE OBSERVATIONAL STUDY OF INTRA OPERATIVE AWARENESS AND RECALL DURING GENERAL ANAESTHESIA
}

\author{
Sanjeev Kumar ${ }^{1}$
}

${ }_{1}^{1}$ Associate Professor, Department of Anaesthesiology, MGM Medical College and Hospital, Jamshedpur, Jharkhand, India.

\section{ABSTRACT}

\section{BACKGROUND}

Awareness under anaesthesia is a rare but extremely unpleasant phenomenon. There are very few studies in the developing world and none from rural areas where incidence of intraoperative awareness may be higher due to increased patient load, limited patient knowledge and lack of trained hospital staff, reliance on older, cheaper but less effective drugs, and lack of proper equipment both for providing anaesthesia, as well as monitoring the patient.

\section{MATERIALS AND METHODS}

This hospital based cross sectional study was performed in M.G.M. Medical College and Hospital, Jamshedpur. Patients undergoing elective surgical procedures in various specialties (including general surgery, orthopedics, ear, nose and throat surgery, urosurgery, and plastic surgery) under general anaesthesia from October 1, 2016 to September 30, 2017, i.e., over a period of 1 year were considered for this study.

\section{RESULTS}

A total of 896 patients completed the questionnaire. Postoperatively, in response to the questionnaire, seven patients reported to have remembered something under anaesthesia. Out of these, three patients described events that were confirmed by operation theatre staff to have occurred whereas they were under anaesthesia.

\section{CONCLUSION}

The incidence of awareness with recall during general anaesthesia is low. The intraoperative monitoring including clinical analysis of anaesthetized patient as well as measurement of end-tidal concentration of volatile anaesthetic agent seems to be sufficient for prevention of episodes of awareness during general anaesthesia.

\section{KEY WORDS}

General Anaesthesia, Awareness, Anaesthesia, Monitoring.

HOW TO CITE THIS ARTICLE: Kumar S. A prospective observational study of intra operative awareness and recall during general anaesthesia. J. Evolution Med. Dent. Sci. 2018;7(50):5347-5351, DOI: 10.14260/jemds/2018/1184

\section{BACKGROUND}

Awareness during anaesthesia has been defined as recall of intraoperative events by a patient operated under general anaesthesia. It is a rare but extremely unpleasant phenomenon. From patient's point of view, intraoperative awareness under anaesthesia is one of the most troublesome anaesthesia-related complications, second only to postoperative nausea and vomiting. ${ }^{1}$ Apart from intraoperative distress, it may result in the development of late postsurgical psychological disorders such as posttraumatic stress disorder.2,3 Moreover, awareness during intraoperative period has also become an important reason for anaesthesia-related compensation claims. Intraoperative awareness is, therefore, described as the second most important complication anesthesiologists (after death) ${ }^{4}$ as well. Various modalities have been tried to assess awareness in anesthetized patients. These include monitoring blood pressure, heart rate, end-tidal anesthetic concentration, and

'Financial or Other Competing Interest': None.

Submission 21-10-2018, Peer Review 24-11-2018,

Acceptance 30-11-2018, Published 10-12-2018.

Corresponding Author:

Dr. Sanjeev Kumar,

Siddheshwar Smriti Kunj,

P. No. 495, Road No. 5,

Hari Om Nagar, Adtiyapur-I,

Jamshedpur-831013, Jharkhand, India.

E-mail: kumar.sanjeev9248@gmail.com

DOI: $10.14260 /$ jemds/2018/1184 bispectral index (BIS). However, none of these modalities have been found to be $100 \%$ effective in detecting awareness under anaesthesia.

Incidence of awareness in developed countries is found to be $0.1 \%-0.2 \% .^{5,6}$ Although there are very few studies in the developing world, the incidence of intraoperative awareness is thought to be somewhat higher as compared to Western world.7 This may in part be due to increased patient load, limited patient knowledge and lack of trained hospital staff, reliance on older, cheaper but less effective drugs, and lack of proper equipment both for providing anaesthesia, as well as monitoring the patient. Problem can be even more complex and multifold in rural areas. However, even after a thorough review of literature, we could not find any study specifically estimating the problem of awareness under anaesthesia in rural areas. Therefore, we conducted this hospital based cross sectional study to assess the incidence of intraoperative awareness during general anaesthesia among patients in rural India and any factors associated with or influencing the same.

\section{MATERIALS AND METHODS}

This hospital based cross sectional study was performed in M.G.M. Medical College and Hospital, Jamshedpur. Patients undergoing elective surgical procedures in various specialties (Including general surgery, orthopedics, ear, nose and throat surgery, urosurgery, and plastic surgery) under general 
anaesthesia from October 1, 2016, to September 30, 2017, i.e., over a period of 1 year were considered for this study.

\section{Inclusion Criteria}

Patients aged 18 years or more, American Society of Anesthesiologist (ASA) Physical Status III or less, with normal neurological status.

Written informed consent was obtained from all patients in their own language before including them in this study.

The technique and drugs used for anaesthesia varied according to patient's preoperative condition, surgical procedure planned, and choice of anesthesiologist; however, all patients considered for this study underwent general anaesthesia with endotracheal intubation and positive pressure ventilation. Induction agent used was either thiopentone sodium or propofol given intravenously followed by muscle relaxant which was either vecuronium or atracurium. After intubation maintenance of anaesthesia was done using $50 \%$ oxygen, $50 \%$ nitrous oxide, and volatile anesthetic (Isoflurane or sevoflurane). During the procedure and throughout the postoperative period, vital signs (including heart rate, oxygen saturation, electrocardiography, and noninvasive blood pressure) of the patients were monitored. Concentration of volatile anesthetic was adjusted according to patient's vital signs, as well as clinical parameters such as pupillary response, sweating, and tearing. Instrumental monitoring of cerebral electrical activity and volatile anesthetic concentration was not carried out, as the same was not available in our institute. None of the patients included in this study underwent surgical procedure under mask ventilation or laryngeal mask airway insertion. Furthermore, total intravenous anaesthesia was not used in any patient. A consultant anesthesiologist (With sufficient experience of general anaesthesia) who was unaware about the patients being included in this study anesthetized all patients. Noise levels in Operation Theater were kept to a minimum, with only minor chat surgeons, anesthesiologist, and operation theater staff. After the completion of surgical procedure, anaesthesia was reversed, extubated, and shifted to postanaesthesia care unit (PACU) after adequate return of consciousness.

Approximately after $1 \mathrm{~h}$ of arrival in PACU, anesthesiologist (Not involved in administering anaesthesia) assessed intraoperative awareness. Anesthesiologist visited the patient and asked questions in his/her own language. First general information such as age, sex, ASA status, anaesthesia technique used, history of chronic drug intake or substance abuse, and any previous history of awareness was obtained. The second part of the questionnaire was a modified form of Brice questionnaire, 8 used by similar studies designed to assess intraoperative awareness, ${ }^{9,10}$ in the past-

- What is the last thing you remember before going to sleep?

- What is the first thing you remember after waking up?

- Do you remember anything between going to sleep and waking up?

- Did you dream during your procedure?

- What was the worst thing about your operation?
After the questionnaire was completed, it was analyzed, and patients were categorized into either having definite awareness, possible awareness, and no awareness. If the event recalled was confirmed by attending personnel present in Operation Theater, or investigators were convinced that memory was real, patients were categorized under definite awareness. If the patient was unable to recall any event definitely indicative of awareness, but memories could have been related to intraoperative events, he/she was categorized as possible awareness. No awareness was defined as a patient with no reported awareness or if the recalled events had a high probability of occurring in immediate pre- or postoperative period. This classification is similar to one used in various other studies assessing intraoperative awareness. Patients having intraoperative dreaming were categorized separately.

Patients having awareness or possible awareness were offered to follow up in anaesthesia outpatient department.

\section{Statistical Analysis}

Data were collected on a Microsoft Excel ${ }^{\circledR}$ sheet and analyzed using Statistical Package for the Social Sciences ${ }^{\circledR}$ version 23 (SPSS Inc., Chicago, IL, USA) for windows. Data were expressed as ratio, percentages and proportions. Fisher's extract test was used for comparison. P $<0.05$ was considered statistically significant.

\section{RESULTS}

A total of 1068 adult patients underwent elective surgical procedures under general anaesthesia. Out of these, 37 patients were ASA Grade IV, so were excluded from the study, 121 patients refused to take part in the study. Of the remaining, 12 had to be shifted to Intensive Care Unit intubated and 2 were disoriented so were thus excluded from the study. There was no disruption of anaesthesia or circuit failure in any case. Hence, a total of 896 patients completed the questionnaire.

Of these 896 patients, $25.89 \%$ of patients were $<30$ years of age, $32.48 \%$ were between 30 and 44 years, $25.78 \%$ were between 45 and 59 years, and remaining $15.85 \%$ were 60 years and above. Nearly $32.59 \%$ of participants were males and the rest were females. As far as education level was concerned, $194(21.65 \%)$ patients were illiterate, 258 (28.79\%) patients studied up to primary standard, 189 (21.09\%) patients till secondary level, 211 (23.55\%) were graduates, and remaining $44(4.91 \%)$ were postgraduates. Based on socioeconomic status, roughly half of the patients were poor (51.01\%), 44.31\% belonged to middle class, and $42(4.61 \%)$ patients were rich. According to ASA grading, $62.95 \%$ of patients were ASA Grade I, $23.32 \%$ were ASA Grade II, and $13.73 \%$ were ASA Grade III. All the patients underwent elective surgical procedures under general anaesthesia with endotracheal intubation using muscle relaxants. A maximum number of patients participating in the present study underwent general surgical procedures (77.01\%), followed by ear, nose, and throat surgery (11.38\%), orthopedic surgery (5.13\%), urosurgery $(4.24 \%)$, and plastic surgery (2.23\%). Among the patients undergoing general surgical procedures, 439 patients (65.72\%) underwent laparoscopic cholecystectomy, 58 (8.68\%) underwent laparoscopic hernioplasty, 14 (2.09\%) 
laparoscopic appendectomy, $25 \quad$ (3.74\%) open cholecystectomy, 30 (4.49\%) modified radical mastectomy,
$16(2.39 \%)$ laparotomy, and remaining 86 patients $(12.87 \%)$ had various other elective surgical procedures.

\begin{tabular}{|c|c|c|}
\hline Sl. No. & Demographic Variables & N (\%) \\
\hline \multirow{5}{*}{1} & \multicolumn{2}{|c|}{ Age (years) } \\
\hline & $<30$ & $237(26.32)$ \\
\hline & $30-44$ & $286(31.20)$ \\
\hline & $45-59$ & $226(27.39)$ \\
\hline & 60 and above & $147(16.04)$ \\
\hline \multirow{3}{*}{2} & \multicolumn{2}{|c|}{ Sex } \\
\hline & Male & $265(30.19)$ \\
\hline & Female & $632(70.36)$ \\
\hline \multirow{6}{*}{3} & \multicolumn{2}{|c|}{ Education } \\
\hline & Illiterate & $190(20.82)$ \\
\hline & Primary & $262(29.64)$ \\
\hline & Secondary & $180(20.12)$ \\
\hline & Graduate & $219(24.23)$ \\
\hline & Post Graduate & $45(5.10)$ \\
\hline \multirow{4}{*}{4} & \multicolumn{2}{|c|}{ Socioeconomic Status } \\
\hline & Poor & 477 (54.89) \\
\hline & Middle Class & $370(41.32)$ \\
\hline & Rich & $49(5.25)$ \\
\hline \multirow{4}{*}{5} & \multicolumn{2}{|c|}{ ASA Grade } \\
\hline & $\mathrm{I}$ & $564(62.95)$ \\
\hline & II & $209(23.32)$ \\
\hline & III & $123(13.73)$ \\
\hline 6 & \multicolumn{2}{|c|}{ Type of Surgery } \\
\hline & General & $660(73.40)$ \\
\hline & Urosurgery & $46(5.09)$ \\
\hline & Plastic Surgery & $20(2.23)$ \\
\hline & Orthopaedics & $50(5.5)$ \\
\hline & Ear, Nose and Throat & $125(14.61)$ \\
\hline \multicolumn{3}{|c|}{$\begin{array}{c}\text { Table 1. Demographic Variables of Patients } \\
\text { Included in the Study }\end{array}$} \\
\hline
\end{tabular}

\begin{tabular}{|c|c|c|c|c|c|c|}
\hline Age & Sex & ASA Grade & Education & $\begin{array}{c}\text { Socioeconomic } \\
\text { Status }\end{array}$ & Surgery & Description of Awareness \\
\hline 45 & Female & II & $\begin{array}{c}\text { Secondary } \\
\text { School }\end{array}$ & Middle Class & $\begin{array}{c}\text { Laparoscopic Right } \\
\text { Pyelolithotomy }\end{array}$ & $\begin{array}{c}\text { Heard operating surgeon talking to his } \\
\text { assistant }\end{array}$ \\
\hline 60 & Female & II & Graduate & Poor & $\begin{array}{c}\text { Modified Radical } \\
\text { Mastectomy }\end{array}$ & $\begin{array}{c}\text { Felt something in her throat along with } \\
\text { inability to move any of their limbs }\end{array}$ \\
\hline 18 & Male & II & Graduate & Middle Class & Hemithyroidectomy & $\begin{array}{c}\text { Felt something in her throat along with } \\
\text { inability to move any of their limbs and } \\
\text { hearing sound of various alarms }\end{array}$ \\
\hline \multicolumn{7}{|c|}{ Table 2. Patients with Definite Awareness under Anaesthesia } \\
\hline
\end{tabular}

\begin{tabular}{|c|c|c|c|c|c|c|}
\hline Age & Sex & $\begin{array}{c}\text { ASA } \\
\text { Grade }\end{array}$ & Education & $\begin{array}{c}\text { Socioeconomic } \\
\text { Status }\end{array}$ & Surgery & Description of Awareness \\
\hline 20 & Female & I & Secondary School & Middle class & $\begin{array}{c}\text { Excision of Fibroadenoma } \\
\text { Breast }\end{array}$ & $\begin{array}{c}\text { Heard the sound of pulse } \\
\text { oximeter }\end{array}$ \\
\hline 60 & Female & I & Secondary School & Poor & Laparoscopic Cholecystectomy & Felt pain in abdomen \\
\hline 32 & Male & III & Illiterate & Poor & Laparoscopic Hernioplasty & Felt pain in abdomen \\
\hline 42 & Female & II & Illiterate & Poor & Laparoscopic Cholecystectomy & $\begin{array}{c}\text { Felt blood pressure cuff } \\
\text { inflating on her arm }\end{array}$ \\
\hline \multicolumn{7}{|c|}{ Table 3. Patients with Possible Awareness under Anaesthesia } \\
\hline
\end{tabular}

\begin{tabular}{|c|c|c|c|c|c|c|}
\hline Sl. No. & Demographic Variables & N (\%) & Awareness N (\%) & Dreaming N (\%) & No Awareness N (\%) & P Value \\
\hline \multirow{3}{*}{1} & \multicolumn{5}{|c|}{ Age (Years) } \\
\cline { 2 - 7 } & $<30$ & $237(26.15)$ & $2(0.33)$ & $50(6.8)$ & $176(18.4)$ \\
\cline { 2 - 7 } & $30-44$ & $286(31.63)$ & $2(0.33)$ & $64(7.5)$ & $220(24.27)$ & 0.012 \\
\cline { 2 - 7 } & $45-59$ & $226(27.93)$ & $1(0.112)$ & $40(4.46)$ & $190(20.25)$ & \\
\hline
\end{tabular}




\begin{tabular}{|c|c|c|c|c|c|c|}
\hline & 60 and above & $147(16.32)$ & $2(0.33)$ & $28(3.5)$ & $110(12.01)$ & \multirow{4}{*}{0.015} \\
\hline \multirow{3}{*}{2} & \multicolumn{5}{|c|}{ Sex } & \\
\hline & Male & $265(30.42)$ & $2(0.33)$ & $65(7.23)$ & $220(24.05)$ & \\
\hline & Female & $632(70.28)$ & $5(0.56)$ & $117(13.14)$ & $479(53.62)$ & \\
\hline \multirow{6}{*}{3} & \multicolumn{5}{|c|}{ Education } & \\
\hline & illiterate & $190(20.05)$ & $2(0.33)$ & $45(5.25)$ & 140 (16.87) & \\
\hline & primary & $262(29.15)$ & 0 & $54(6.58)$ & $203(22.15)$ & \\
\hline & Secondary & $180(20.85)$ & $3(0.375)$ & $43(4.8)$ & $143(15.95)$ & \multirow{3}{*}{0.019} \\
\hline & Graduate & $219(24.63)$ & $1(0.112)$ & $37(4.5)$ & $172(19.07)$ & \\
\hline & Post Graduate & $45(5.02)$ & 0 & $7(0.78)$ & 37 (4.13) & \\
\hline \multirow{4}{*}{4} & & & economic & & & \multirow{4}{*}{0.038} \\
\hline & Poor & 477 (54.35) & $4(0.45)$ & $88(9.04)$ & $360(40.82)$ & \\
\hline & Middle Class & $370(41.05)$ & $3(0.33)$ & $86(8.9)$ & $305(34.35)$ & \\
\hline & Rich & $49(5.14)$ & 0 & $9(1.4)$ & $33(3.5)$ & \\
\hline \multirow{4}{*}{5} & \multicolumn{5}{|c|}{ ASA Grade } & \multirow{4}{*}{0.024} \\
\hline & $\mathrm{I}$ & $564(62.95)$ & $2(0.33)$ & $117(13)$ & $445(49.67)$ & \\
\hline & II & $209(23.32)$ & $4(0.45)$ & $41(4.56)$ & $164(18)$ & \\
\hline & III & $123(13.73)$ & $1(0.112)$ & $28(3.20)$ & $90(10.32)$ & \\
\hline \multirow[t]{6}{*}{6} & & & pe of Surg & & & \multirow{6}{*}{0.057} \\
\hline & General & $660(73.04)$ & $6(0.67)$ & $150(16.74)$ & $506(56.12)$ & \\
\hline & Urosurgery & $46(5.57)$ & 0 & $7(0.78)$ & $30(3.5)$ & \\
\hline & Plastic Surgery & $20(2.23)$ & 0 & $4(0.45)$ & $16(1.79)$ & \\
\hline & Orthopaedics & $50(5.5)$ & 0 & $6(0.67)$ & $40(4.5)$ & \\
\hline & Ear, Nose and Throat & $125(14.02)$ & $1(0.112)$ & $20(2.23)$ & $103(11)$ & \\
\hline
\end{tabular}

\section{DISCUSSION}

Incidence of awareness under anaesthesia with postoperative recall was found to be $0.33 \%$ in our study. However, if patients with possible awareness were also included, incidence of awareness under anaesthesia would become $0.78 \%$. This occurrence is higher than reported by most studies conducted in the Western world which estimated the incidence to be between $0.1 \%$ and $0.2 \%$. However, in a study by Errando et al. done on over 4000 patients, incidence of awareness with recall was found to be $1.0 \%$ among all patients operated under anaesthesia and $0.8 \%$ after removing high-risk cases.

These awareness cases were followed retrospectively to study the intraoperative events and vitals, anaesthetic technique and preoperative status, including demographic data. We could not find any significant predictor of possible awareness in these cases of awareness. All the cases were monitored intraoperatively by using entropy from induction to emergence at fixed intervals of time and in these 2 cases of awareness entropy was found consistently above 60 but there was no association between increased entropy readings and the incidence of awareness as many patients had entropy above 60 but did not report awareness in our study.

Awareness is caused by the administration of general anaesthesia that is inadequate to maintain unconsciousness and to prevent recall during surgical stimulation. Common causes include large anaesthetic requirements, equipment misuse or failure and smaller doses of anaesthetic drugs.

Various studies found an increased risk of awareness with sicker patients undergoing major surgery, this finding may reflect the use of smaller anaesthetic doses and light anaesthetic techniques in sicker patients.

In many cases, awareness during anaesthesia is a potentially avoidable adverse anaesthetic outcome. In light of follow up studies suggesting that such victims of awareness may exhibit significant psychological after effects such as PTSD, attempts to further reduce its incidence are warranted.

Because awareness occurred despite the usual clinical monitoring of anaesthetic depth (BP, HR and end tidal anaesthetic monitoring), a monitor of cerebral function and depth of anaesthesia may be of theoretical benefit.

The limitation of our study is that it did not assess the long-term psychological sequelae of intraoperative awareness and recall among the victims.

\section{CONCLUSION}

The incidence of awareness with recall during general anaesthesia is low. Intraoperative monitoring including clinical analysis of anaesthetized patient as well as measurement of end-tidal concentration of volatile anaesthetic agent seems to be sufficient for prevention of episodes of awareness during general anaesthesia.

\section{REFERENCES}

[1] Mihai R, Scott S, Cook TM. Litigation related to inadequate anaesthesia: and analysis of claims against the NHS in England 1995-2007. Anaesthesia 2009;64(8):829-35.

[2] Bischoff P, Rundshagen I. Awareness under general anaesthesia. Dtsch Arztebl Int 2011;108(1-2):1-7.

[3] Ziętkiewicz M, Nestorowicz A. Intraoperative awareness - recommendations of the Committee on Quality and Safety in Anaesthesia, Polish Society of Anaesthesiology and Intensive Therapy. Anaesthesiol Intensive Ther 2012;44(2):57-62.

[4] Brice DD, Hetherington RR, Utting JE. A simple study of awareness and dreaming during anaesthesia. $\mathrm{Br} \mathrm{J}$ Anaesth 1970;42(6):535-42.

[5] Ghoneim MM, Block RI, Haffarnan M, et al. Awareness during anaesthesia: risk factors, causes and sequelae: a review of reported cases in the literature. Anesth Analg 2009;108(2):527-35. 


\section{Jemds.com}

[6] Ghoneim MM, Block RI, Dhanaraj VJ, et al. Auditory evoked responses and learning and awareness during general anaesthesia. Acta Anaesthesiol Scand 2000;44(2):133-43.

[7] Leslie K, Skrzypek H, Paech MJ, et al. Dreaming during anaesthesia and anesthetic depth in elective surgery patients: a prospective cohort study. Anesthesiology 2007;106(1):33-42.

[8] The R Development Core Team. R: a language and environment for statistical computing. R Foundation for Statistical Computing, Vienna, Austria 2018. http://www.R-project.org/

\section{Original Research Article}

[9] Mashour GA, Shanks A, Tremper KK, et al. Prevention of intraoperative awareness with explicit recall in unselected surgical population: a randomized comparative effectiveness trial. Anesthesiology 2012;117(4):717-25.

[10] Ghoneim MM. Awareness during anaesthesia. Anesthesiology 2000;92(2):597-602. 